\title{
Exploration and Practice of Talents Training Mode for Higher Education under Belt and Road Policy
}

\author{
Liu Yiqun \\ School of Automotive Engineering \\ Harbin Institute of Technology \\ Weihai, China \\ Zhou Xiaojing* \\ Logistics Security Department \\ Harbin Institute of Technology \\ Weihai, China \\ *Corresponding Author: lyq.new@163.com
}

\author{
Li Xue, Zhang Wenwen \\ School of Economics and Management \\ Harbin Institute of Technology \\ Weihai, China \\ Wang Zhuo \\ Comprehensive Management Office \\ Anqiu Finance Bureau \\ Weifang, China
}

\begin{abstract}
With the implementation of the Belt and Road, the demand for the internationalization of higher education is getting higher and higher. The need of it for internationalized talents is reflected in language skills and professional knowledge, more importantly, it is reflected in its comprehensive and complex characteristics. Based on the analysis of higher education, this paper puts forward some requirements on personnel training in higher education with the aim of promoting cultural exchange, training international talents and building a science and technology innovation platform. At this stage, colleges and universities set up alliances with colleges and universities of the new Silk Road and relying on their superior disciplines to continuously raise the quality of internationalized university and increase the reserve of Chinese higher talent in the strategy of the Belt and Road.
\end{abstract}

Keywords-Higher education; Belt and Road; Talents cultivation mode; New silk road university alliance

\section{INTRODUCTION}

The Belt and Road refers to the "Silk Road Economic Belt" and the "Silk Road on the Sea". This strategy uses the historical symbol of the ancient Silk Road and proactively forms partners with countries and regions along the road to jointly create politics Mutual trust, economic integration, culturally inclusive community of interests, community of destiny and community of responsibility. Building on the existing dual multilateral mechanisms between China and other countries and using the platform for regional cooperation, Belt and Road will not rely solely on existing mechanisms such as the Eurasian Economic Union, China-ASEAN (10+1) Overlap or competition, but also to inject new meaning and vitality [1].

The Silk Road is not only a road to trade in goods, but also a road of knowledge exchange. The exchange of goods and knowledge has brought the collision and innovation of ideas and concepts. For example, although Buddhism originated from India and was inherited in Southeast Asia, it flourished in China. Although Confucianism originated in China, it was also

Project (BKQN201608) Supported by Harbin Institute of Technology at Weihai, and Project (HIT (WH) 201601) Supported by the Scientific Research Foundation of Harbin Institute of Technology at Weihai. praised by thinkers such as Quay and Voltaire in Europe, and Confucius Institutes are all over the world. This is all about the charm and effectiveness of cultural exchange [2]

Under the new normalization of the Belt and Road, through systematic international exchange and cooperation, the system of institutional self-confidence and cultural self-confidence of Chinese institutions of higher education will be passed on to train more ambassadors for international friendship and disseminate the cultural, ideological and spiritual outlook of China from higher education institutions, which is the responsibility and mission of high education. For a long time, the internationalization of education in our country has lagged behind the internationalization of trade and seriously affected the long-term planning and development of Chinese enterprises after they "went global" and marched into the international market. In view of this situation, education should follow the path of going abroad and cultivate the outstanding employees absorbed by the enterprises in the locality into professionals who possess both professional knowledge and Chinese culture, and can speak Chinese. Then they will become the backbone of the enterprise and greatly reduce the cost of human resources so that they can better serve their businesses and help the Belt and Road.

\section{Current Situation Analysis of Talents Cultivation MODE UNDER BELT AND ROAD}

With the launching of the "Belt and Road Initiative" International Cooperation Summit, the process of internationalization of China's higher education will be further accelerated. The new Silk Road University Alliance was launched by Xi'an Jiao Tong University, an institution of higher learning along the "ancient Silk Road". Founded on May 22, 2015, the headquarters of the new Silk Road is located in the science and technology innovation port in western China. So far, nearly 22 countries and regions and 100 universities have joined it [3]. The new Silk Road University Alliance is a non-governmental, non-profit and international cooperation 
platform for higher education jointly established by higher education institutions both at home and abroad. It mainly covers personnel training, inter-university exchanges, cultural exchanges, policy research, scientific research cooperation, Medical services and economic facilities. The aim is to promote exchanges and cooperation between universities in countries along the "New Silk Road Economic Belt", to promote understanding and friendship among undergraduates from all over the world. Cultivate high-quality and compound talents with international vision and ability, enhance the comprehensive ability of talents, serve the development and construction along the "New Silk Road Economic Belt" and in Eurasia.

In addition to regular forums or the formation of university alliances, some colleges and universities with academic characteristics rely on their academic strengths to enhance the cultivation of scarce professionals in Belt and Road Initiative.

Beijing Polytechnic University constantly adjusts the work of international students by focusing on setting up a number of high-level recruitment platforms to cover 40 countries along Belt and Road initiative and cultivating "China-based" engineering talents that meet the development needs of Chinese enterprises for countries and regions along Belt and Road. In addition, in 2016, the two sides signed the Framework Agreement on Comprehensive Strategic Cooperation with Yunnan Province, launched the provincial-school cooperation and proactively integrated the "Belt and Road Initiative". China University of Petroleum (Beijing), in view of its desire for oil professionals, continuously expands its overseas operations and joint ventures and collaborates in the training of international order-oriented professionals in the oil field. Beijing University of Chemical Technology focused on building a cooperation platform for the Belt and Road national education community and took the initiative to cooperate with universities and enterprises in the Middle East, three countries including Saudi Arabia, the UAE and Iran. In addition, the company signed a cooperation agreement with domestic enterprises to train Indonesian students to come to China and declared and approved the project of jointly sponsoring the Indonesian Student Scholarship Program in order to serve the high-level talent strategy of "the Belt and Road".

\section{Research ON TALENT CUltivation Method Based ON BELT AND ROAD}

Belt and Road is a major strategic concept for raising the level of China's opening to the outside world and also provides a major strategic opportunity to further promote the internationalization of higher education, deepen the comprehensive reform in the fields of higher education and improve the quality of education. So how to combine the situation and the characteristics of running a school and seek opportunity of development is worth further discussion by colleges and universities [4].

\section{A. Communicate with the relevant countries, promote cultural understanding and recognition}

For most countries along Belt and Road, culture has its common ground. In particular, some countries in Southeast Asia are inextricably linked to China. Cultural communication is silent and subtle, either in everyday communication or in travel, regardless of the form, the more systematic and comprehensive approach is by education, especially higher education. So higher education in cultural transmission occupy a pivotal position.

Academic, educational and cultural exchanges are important means of public diplomacy in the country. We will actively carry out international education and academic exchanges, promote cultural communications and exchanges among citizens of the countries along the Belt and Road, and promote mutual understanding and trust between neighboring countries and China so as to achieve common cooperation [5]. Specifically, we have established the "Silk Road Higher Education Cooperation Forum" with international influence to promote the diplomacy of Education Forum and attract the world's authorities, especially the principals in the relevant disciplines in the countries along the Belt and Road, such as university presidents, experts and scholars, come to China to attend the meeting, promote university cooperation and deepen cultural exchange. The establishment of Confucius Institutes in countries along Belt and Road to spread classical Chinese Confucianism and exchange of humanities and education should be used to promote regional cultural integration [6].

\section{B. Cooperate with relevant countries, and foster international talents}

The sustained promotion of the Belt and Road strategy requires more qualified personnel. To solve the problem of personnel training will greatly push forward the strategic process of "the Belt and Road". Therefore, to promote the implementation of the "Belt and Road" strategy, we must uphold the strategy of prioritizing people. Only with good people can the country seize the opportunities and win the initiative in the globalization of competition. Our country has always taken the strategy of rejuvenating through science and education and building a strong country with talent as the basic education strategy. At this stage, according to the demand of the Belt and Road strategy, as a higher education institution with a sound training system, we must immediately devote ourselves to training a group of internationalized personnel. We should focus on the following aspects: foreign language and engineering practices, international rules and laws, international perspectives and global awareness of ideas and strategies.

Colleges and universities should focus on the urgent needs of subjects and skills in countries along the Belt and Road, combine their own characteristics and the advantages of academic resources in academic disciplines, highlight key points and characteristics, and promote high-level international personnel programs. They have to adopt various forms and methods, such as school-enterprise cooperation. We must speed up the education of overseas students in China and speed up the training of high-level international talents for Chinesefunded enterprises to promote the Belt and Road project. We 
will expand the enrollment and training scale of foreign students coming to China and create a complete system of education and training for overseas students so as to cultivate a group of internationalized talents who have known China and have achievements. We should pay special attention to the political, economic and social differences in different countries and regions in the training of overseas Chinese students, help them understand Chinese history and culture, and deepen their goodwill and friendship toward China. In addition, the state should also focus on engaging in deeper-level higher education cooperation, not only to attract foreign students to China but also to send a batch of talented people with strong learning abilities to exchange and learn from countries along the AsiaEurope border. When they back to china, can return the motherland, introduce advanced technology and knowledge. In this process, we should pay attention to avoiding the loss of higher education. By combining "bringing in" with "going out" strategies, we can continuously improve the quantity and quality of qualified personnel, continuously deepen the reform and opening up, spare no efforts in talent pooling for the national strategy and promote the process of national modernization.

\section{Oriented by science and technology, construct innovation platform}

In the crucial period of transition from a big manufacturing country to an industrial power in our country, under the background of "mass innovation and entrepreneurship", cultivating higher education personnel is a key to our country. In the process of training, we must closely integrate innovation with practice, constantly adjust and perfect the model of innovation and training, establish and improve various rules and regulations, and establish a comprehensive science and technology innovation platform. As the saying goes, "science and technology are the primary productive forces". In the future, with advanced science and technology, China can have a strong voice. As the progress of economy, China plays an increasingly important role in the international arena. At same time, all colleges and universities should continue to strengthen scientific and technological innovation and education, establish innovation platform for the cultivation and growth of personnel to provide a good environment [7].

Colleges and universities should be at the forefront of international academic and regional economic and social development, acquire the most advanced knowledge and skills, and adhere to academic and national goals as the orientation and strengthen discipline professional infrastructure, especially in Belt and Road strategy, which is in line with the national goal of disciplines, and actively crack the dilemma in science, technology and engineering. For example, the special "the Belt and Road" symposium will be held, set up a special website to speak freely and support government decisions. The "Silk Road University Alliance" will be set up as a bridge and link for the deep cooperation between Chinese universities and universities and colleges along the country lines. National or regional research institutes to promote collaborative innovation in education cooperation and science and technology between China and other countries along the country and to make it an information sharing platform, an academic research exchange platform and an industrial technology research and development platform for "the Belt and Road" scientific and technological cooperation.

The state must make the Belt and Road become a path of innovation and growth in our country. Innovation is an important force in promoting social development. The "Belt and Road" construction itself is strategic innovation and institutional innovation. To improve the Belt and Road strategy also requires innovation to provide impetus and requires science and technology to promote its development. We must adhere to technology-driven innovation and promote cloud computing, big data, smart city construction and innovationdriven development. We will strengthen cooperation in cuttingedge fields such as nanotechnology, digital economy, artificial intelligence, and quantum computers, and connect them into the 21 st century's modern digital silk road. In the Internet age, we must create a space platform for young people of all countries to accomplish the dreams of young people. We must continue to promote the integration of science and technology with industry, science and technology and economy, science and technology and finance, gather innovative resources and optimize the environment for innovation.

\section{PRactice AND ApPlication of TAlents Cultivation MODE FOR Higher EDUCATION UNDER BELT AND ROAD}

\section{A. Join the new Silk Road University Alliance}

Harbin Institute of Technology has joined the new Silk Road University Alliance. According to the major national strategic and geographical advantages of the Belt and Road, we have taken into consideration the construction status quo and future plans of the Eurasian Plate, the Sino-Russian characteristics and the alliance of China-Russia Polytechnic University. Put forward to carry out "Ao-Shan Eurasian Science and Technology Forum" concept. It hopes to build on Asturias and New Silk Road University alliances to build the top universities and unite high-caliber talents in various fields and actively build a platform for scientific and technological innovation, high-level personnel training and humanistic exchanges in the Eurasian Regional Progress and Integration Promote Common Development. They will strengthen personnel training and research cooperation to strengthen interschool exchanges and inter-regional cooperation and enhance cooperation modes and levels in-depth exchange of views, to make efforts for the development of higher education in the Belt and Road Practice of management system and incentive mechanism.

\section{B. Training all-round talents}

Shandong Province, as a strategic maritime strategic pillar of the national "the Belt and Road" strategic plan and a key area along the New Eurasian Continental Bridge Economic Corridor, all Shandong colleges and universities should coordinate well with the overall orientation of Shandong Province in the Belt and Road. Harbin Institute of Technology at Weihai is located in Weihai, Shandong Province, with its natural geographical advantages. The school establishes the International College of Marine Science and Engineering and runs a joint school with top-tier universities in the world to 
raise the standard of running schools and cultivate high-quality talents. Based on Weihai and serving Shandong, the school provides support to the economic development of the blue peninsula in Shandong and Weihai and the national marine economy and construction, serves as the naval strategic pivot for the country's "the Belt and Road" strategic plan and contribute to the build the new Eurasian continent Bridge emergency corridor.

Harbin Institute of Technology at Weihai deployed relevant strategies in fostering talents for the Belt and Road strategy. Through cooperation with world-class international and international universities, it has established an international teaching institution and joint international teaching resources, Will train a group of internationally competitive students worldwide to leave behind talents for the globalization of the economy and industrial development [8].

\section{Set up science and technology innovation platform based on Industry - Academy - Research cooperation}

In order to explore how student organizations fit the Belt and Road strategy, HIT Racing Team (HRT) was built in 2009. As one of the earliest-founded formula racing teams in China, Eight year's development makes HRT bigger, stronger and more innovative. HRT has already designed and manufactured 8 engine-driven cars, 4 electric cars and 2 Baja cars for FSAE, and some racing cars are shown in Fig. 1.

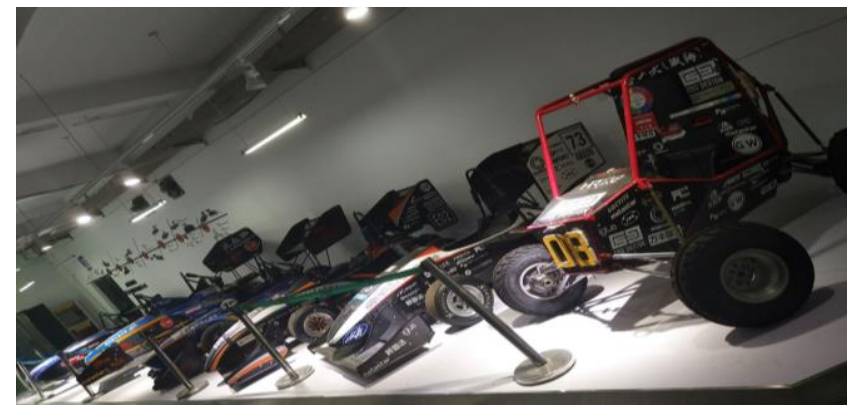

Fig. 1. Racing cars of HRT

Combined with the overall layout of the automotive industry and the overall demand for automotive engineering professionals in China, HRT adjusted its direction and continuously focused on the training of innovative talents based on its own development. Conduct research and interviews with three groups of enterprises, schools and students to find out the positioning of colleges and enterprises in co-cultivation and clarify the rights and responsibilities of both parties. Throughout the training process, "school tutors" and "business tutors" can be implemented. Double tutorial system to strengthen the cooperation between school and enterprise. In response to the demand of enterprises for the knowledge structure of technical personnel, the operational management system and incentive mechanism for scientific and technological innovation of university students are perfected and perfected [9].

Through the team's training, team members in-depth combined theoretical knowledge of the classroom and racing design, have strengthened the practice of scientific and technological innovation, improved team members' hands-on ability and stimulated creativity. At the same time, a large number of innovative achievements have been applied to the racing car, which is also a source of continuous improvement of HRT team technology. In the following year, HRT used the first carbon fiber monomer shell in China. HRT is independently designed and manufactured the only innovative carbon fiber all-in-one shell body. The fleet leads the domestic FSAE trend with its leading domestic Carbon fiber monomer shell body, full carbon fiber aerodynamics package and advanced technology such as paddle type pneumatic shift. The team has participated in the top national and world competitions in China, Germany and Japan, and has achieved outstanding track records. The team has gained recognition and support from the outside world for its technical strength and pursuit of innovation. In 2016, the HRT Electricity team and Baja team won the double winners of domestic undergraduate sports. This is a profound result of our practice and encourages us to keep moving forward.

\section{CONCLUSIONS}

Making talents localization and internationalization is important part that higher education needs to focus on. This paper pay attention to promoting cultural exchanges, training of international personnel, construction of science and technology innovation platform for higher education personnel training to meet the new requirements. And in the practical phase has made more significant achievements, in the future China will continue to enhance the quality of personnel training, improve the level of internationalization.

\section{REFERENCES}

[1] W. D. Liu, "Scientific understanding of the Belt and Road Initiative of China and related research themes," Progress in Geography, vol. 34, no. 5, pp. 538-544, 2015.

[2] Mumtaz Hussain, "One Belt and One Road: An Emerging Transcontinental Trade Heaven," Shandong University, 2017.

[3] G. Xing, Y. Wang, "The Strategic Thinking and Fund Guarantee of Educational,Scientific and Cultural Preferential Development in "One Belt and One Road"," Journal of Xian Jiaotong University, 2016.

[4] P. Y. Li, H. Qian, K. W. F. Howard, et al., "Building a new and sustainable "Silk Road economic belt"," Environmental Earth Sciences, vol. 74, no. 10, pp. 7267-7270, 2015.

[5] L. J. Mu, "Reconsider the cultivation of intercultural communicative competence in the context of the Belt and Road," Journal of Shaanxi Xueqian Normal University, vol. 33, no. 3, pp. 6-9, 2017.

[6] J. Gong, X. Q. Ding, "The New Silk Road as an Emerging Model of Regional and International Economic Cooperation - A Brief Review of the International Symposium on "The New Silk Road and China-Africa Economic Relations"," International Critical Thought, vol. 5, no. 4, pp. 529-532, 2015.

[7] Y. Song, L. Yang, R. T. Lei, et al., "Construction and Practice of Students' Science \& Technology Innovation Platform," Research \& Exploration in Laboratory, vol. 26, no. 9, pp. 72-74, 2007.

[8] M. H. Chen, Y. Mou, "A Study on the Strategy of Cultivating Foreign Language Talents in Hainan Colleges and Universities for the Construction of "The Belt and Road Initiative"," Journal of Hubei Correspondence University, vol. 30, no. 18, pp. 21-24, 2017.

[9] C. Y. Zang, T. Wu, et al., "Personnel Training Ways of Talents Based on Scientific Innovation Activities for College Students," Journal of Electrical \& Electronic Education, vol. 38, no. 2, pp. 1-4, 2016. 